\title{
Post-tagging behaviour and habitat use in shortnose sturgeon measured with high-frequency accelerometer and PSATs
}

\author{
Franziska Broell ${ }^{1 *}$, Andrew D. Taylor ${ }^{2}$, Matthew K. Litvak², Andre Bezanson ${ }^{3}$ and Christopher T. Taggart ${ }^{1}$
}

\begin{abstract}
Background: External tagging of fish using pop-up satellite tags (PSATs) can cause trauma and stress associated with capture, handling, tagging injury and tag placement that impedes body function and mobility, and these can affect the behaviour of the fish. We measured short-term (days) post-release behavioural response of estuarine shortnose sturgeon to tagging with PSATs and high-frequency accelerometers.

Methods: We developed a secure, low-noise attachment method for high-resolution ( $50 \mathrm{~Hz}$ ) accelerometer PSATs in shortnose sturgeon. The archived time series of acceleration was used to determine sturgeon post-tagging activity, estimate swimming speed, erratic behaviour and behavioural clusters in relation to ambient light level and temperature, depth and tidal flow.

Results: Short-term (hours) post-release response was characterized by resting periods on the river bottom and decreased swimming activity that was associated with individual-specific modulations in the swimming gait and high-energy burst acceleration movements. Locomotion routines suggested a relation to tidal flow, yet the shortterm time series did not allow for routine movements to be classified.

Conclusions: The approach used provides a useful method of revealing behavioural modifications during the postrelease recovery period of PSAT-tagged fish. We discuss how short-term (acute) effects on behaviour and potential longer-term (chronic) effects on survival are especially relevant in tagging studies.
\end{abstract}

Keywords: Sturgeon, Pop-up satellite archival tags, Accelerometers, Tagging and handling effects, Behaviour, Swimming speed

\section{Background}

Quantifying the spatial-temporal distribution of freeranging animals in marine environments is problematic due to the lack of direct observations [1,2]. Animalborne archival tags provide a means to monitor highresolution movement and behaviour of aquatic animals through a suite of sensors providing in situ measurements of temperature, depth or acceleration, etc. [1, 3]. Such data can be used to quantify variation in behaviour, energetics and habitat use and provide objective measurements of how animals interact with each other and

\footnotetext{
*Correspondence: franziskabroell@dal.ca

1 Oceanography Department, Dalhousie University, 1355 Oxford Street, Halifax B3H 4R2, Canada

Full list of author information is available at the end of the article
}

respond to their environment [1]. Most recently, accelerometer sensors have been used for remote measurements of fine-scale movements among free-swimming fish [4-6] in controlled mesocosms [7-11], as well as in the wild $[1,4-6,12,13]$. Typically, in situ measurements are collected using implanted archival tags or pop-up satellite tags (PSATs) that are deployed over weeks to years [14]. PSATs release after some pre-set time, come to the surface and transmit processed data to a satellite system [15-18].

A major challenge in using PSAT accelerometers is the PSAT attachment that typically relies on a single-point attachment where the release mechanism located at the leading end of the tag is tethered to the fish using various anchoring methods [19-23]. While this provides the 
most reliable tag release [14], it causes increased drag due to the large cross-sectional area [24] and acceleration measurements can be compromised due to the decoupling of animal movement from the fluttering movement of the tag. The solution to this problem is a rigid tag mount achieved by a longitudinal two-point attachment, similar to methods used for air-breathing animals (e.g. penguins, pinnipeds, [25]) and sharks [26].

In situ capture-recapture or tag-recovery studies using conventional or electronic tags are typically based on the assumption that there is no significant effect of the tag on the fish and that tags are not lost or shed through erratic swimming [27]. If invalid, this assumption can lead to compromised estimates of the metrics used to estimate population distribution as well as activity patterns and energy budgets [27]. This is especially problematic in biologging studies where data from a few (typically $<10$ ) individuals are collected to make inferences about entire populations [1]. The trauma and stress associated with capture, handling and tagging injury, or tag placement that impedes body functions and mobility can affect the behaviour of the tagged fish $[27,28]$. Observed behavioural changes have been related to the physiological and biochemical effects of exhaustive exercise associated with capture and handling $[29,30]$ along with blood acidosis and high blood lactate levels that have been reported for tuna, sharks, and billfish subjected to capture and handling [31, 33].

In an attempt to collect high-resolution accelerometer data to determine fish movement as well as postrelease behaviour and response to tagging and stress, we designed a short-duration (days) PSAT study in a tidally influenced river where physical tag retrieval could be achieved. We first developed a tagging protocol for a secure attachment of a tri-axial accelerometer PSAT. We then investigated the response to tagging and handling and the associated behavioural and locomotion routines in relation to local environmental variables (temperature, light, depth, sea level). The study animal was the shortnose sturgeon (Acipenser brevirostrum) that inhabits the Saint John River, NB, Canada, and its tributaries. This species has been reported to display behavioural and movement-related response to bathymetry and tidal flow [32]. Along the east coast of North America, most shortnose sturgeons remain in their natal river and estuary [34,35]. Their abundance is less than the minimum estimated for a viable population [35] mainly due to anthropogenic impacts such as bycatch and poaching, blockage of spawning runs by dams and the regulation of river flows $[35,36]$. Thus, they are listed as endangered under the Endangered Species Act 1973 [35] throughout their US range. In Canada, they are listed as a species of special concern [37]; however, the
Saint John river-system population is large and is estimated to be between 7000 and 28,000 individuals [38]. There is an active recreational catch-and-release fishery in the river that is regulated by minimum size restrictions (>1.22 $\mathrm{m}$, [38]); however, they are also a bycatch in the alewife (Alosa pseudolaregnus), shad (Alosa sapidissima) and eel (Anguilla rostrata) fisheries [38]. Therefore, it is appropriate to develop approaches to assess the potential impact of capture, handling and release of this species. Our objective was to develop and test the use of accelerometers on measuring locomotory behaviour post-release. This is the first step in developing a tagging system that can be used to test post-release behaviour and potentially physiological response to capture, handling and release (e.g. [39-41]). Therefore, we tagged five shortnose sturgeons with high-frequency accelerometers mounted on PSATs that recorded environmental variables over a 2-day period.

\section{Materials \\ Study site and animals}

Shortnose sturgeons were caught in a recreational fishing derby in the Kennebecasis River, New Brunswick (45.49N, 65.92W, Additional file 1: Fig. S1). The river is estuarine with a low-flow, fjord-like bay connected to the Saint John River and the Bay of Fundy with very little freshwater flux and minor inflow [42, 43]. Salt water can spill over the downstream sill during a flood tide if the conditions are correct. Experiments were conducted during a spring tide (maximum tidal amplitude $7.6 \mathrm{~m}$, minimum amplitude $1.0 \mathrm{~m}$; Saint John tidal gauge station 65, 45.251W 66.063N, Environment Canada).

Shortnose sturgeons $(n=5$, Table 1$)$ of total length $(l$; $\mathrm{m})$ ranging from 0.83 to $1.09 \mathrm{~m}(0.96 \mathrm{~m} \pm 0.096$, average $\pm \mathrm{SD})$ in fork length and $0.94-1.21 \mathrm{~m}(1.06 \mathrm{~m} \pm 0.11$, average $\pm \mathrm{SD})$ in total length with mass $(m ; \mathrm{kg})$ between 4.00 and $12.8 \mathrm{~kg}(6.55 \mathrm{~kg} \pm 3.68$, average $\pm \mathrm{SD})$ were caught by recreational anglers involved in the annual October catch-and-release sturgeon fishing derby. Fish were transferred to a holding pen set in the river where they were kept for $\sim 48 \mathrm{~h}$ (Table 1), and each fish was tagged with a SeaTag-MOD PSAT $(27.5 \mathrm{~cm}$ length, $2.5 \mathrm{~cm}$ diameter at narrowest point, $4 \mathrm{~cm}$ in diameter at widest point, $145 \mathrm{~g}$ in air, Desert Star Systems LLC, USA), upon which we mounted a MBLog PT-1 tri-axial accelerometer (23 $\mathrm{mm}$ diameter, $50 \mathrm{~cm}$ length, $18.8 \mathrm{~g}$ in air, Maritime bioLoggers, Halifax, Canada) and a V9 acoustic transmitter $(24 \mathrm{~mm}$ length, $5 \mathrm{~mm}$ diameter, $3.6 \mathrm{~g}$ in air, VEMCO, Amirix, Halifax, Canada) (Additional file 2: Fig. S2). The PSATs recorded temperature $\left( \pm 0.1{ }^{\circ} \mathrm{C}\right)$, depth $( \pm 2.15 \mathrm{~m})$ and ambient light (75 microLux resolution) at $1 \mathrm{~Hz}$. The accelerometers recorded tri-axial acceleration at $50 \mathrm{~Hz}$ 
Table 1 Summary data associated with shortnose sturgeons that were caught and tagged in the Kennebecasis River, New Brunswick, with PSATs and accelerometers in October 2012

\begin{tabular}{|c|c|c|c|c|c|c|c|}
\hline $\mathrm{TL}(\mathrm{m})$ & $\mathrm{FL}(\mathrm{m})$ & Mass (kg) & Date tagged & Pop-up date & $\begin{array}{l}\text { PSAT recording } \\
\text { duration (hh:mm) }\end{array}$ & $\begin{array}{l}\text { Accelerometer } \\
\text { recording duration (hh:mm) }\end{array}$ & $\begin{array}{l}\text { Holding time } \\
\text { (hh:mm) }\end{array}$ \\
\hline 1.21 & 1.09 & 12.8 & $10 / 02 / 2012$ & 10/04/2012 & $36: 22$ & $44: 54$ & $49: 42$ \\
\hline 1.12 & 0.96 & 6.89 & 10/02/2012 & 10/04/2012 & $35: 46$ & $22: 26$ & $50: 18$ \\
\hline 1.05 & 0.92 & 4.04 & 10/02/2012 & 10/04/2012 & $45: 46$ & $46: 30$ & 49:09 \\
\hline 0.98 & 0.90 & 4.00 & 10/08/2012 & 10/10/2012 & $0: 00$ & 09:18 & $\sim 48: 00$ \\
\hline 0.94 & 0.83 & 5.07 & 10/08/2012 & 10/10/2012 & 0:00 & $20: 42$ & $\sim 48: 00$ \\
\hline
\end{tabular}

Data include total length $(\mathrm{TL}, \mathrm{m})$, fork length $(\mathrm{FL}, \mathrm{m})$, mass $(\mathrm{kg})$ deployment and recovery dates and data recording durations

(10-bit resolution) at $\pm 6 g_{0}$. The entire package is hereafter referred to as the 'tag' (167.4 g in air, 1.15-3.6 \% fish body weight).

\section{Tag attachment and release}

Rigid tag attachment (Additional file 2: Fig. S2) was achieved by a lock and slide mechanism and two dorsal attachment points: one anterior and one posterior. The tag release section, located at the tip of the PSAT, was attached to latex surgical tubing $(0.16 \mathrm{~cm} \mathrm{ID,} 0.32 \mathrm{~cm}$ OD, $0.08 \mathrm{~cm}$ wall) passed through a single bony scute to the right lateral side of the fish and attached to a Petersen disc. The surgical tubing provided sufficient tension to hold the tag in place on the dorsum. The posterior attachment was located $\sim 25 \mathrm{~cm}$ from the anterior attachment, anterior to the dorsal fin. It consisted of a one-way female slide-lock plate attached to two scutes on the left lateral side and to a Petersen disc on the right lateral side and connected using surgical tubing. The male slide plate attached to the tag was then slid into the slide-lock plate where it was held in place by the tension created by the surgical tubing anchored anterior to the tag. The PSAT tip was equipped with an explosive release mechanism. Once released from the anterior anchor, the tag slid out of the slide-lock plate, facilitated by the posterior tag buoyancy-package and drag. Since all attachments to the fish were made using dissolvable suture material, the slide-lock plate and Petersen discs were expected to eventually release from the animal.

Once tagged, the fish were released into the river with tags that were programmed to pop up after $48 \mathrm{~h}$. Following their release, fish location was established daily using a small vessel and a VEMCO directional hydrophone (VH110) connected to a receiver decoder (VH100) following the Taylor and Litvak [44] protocol. This allowed us to determine the location of the tagged fish prior to the scheduled PSAT release time. This proved to be essential given that although all tags did pop-up, no ARGOS transmission for locating the tags was received.

\section{Methods}

Data

Acceleration data over a total of $144 \mathrm{~h}$ were obtained from the five tags (Table 1). Two PSATs failed to record environmental data, and three datasets of temperature, depth and light spanning periods of 35-45 h (Table 1). To ensure that the rigid attachment provided reliable accelerometer data, acceleration noise was compared to data obtained from mesocosm studies on the same species [11] wherein the tags were firmly attached to the fish. We assumed that similar levels of noise indicated sufficient rigid attachment. Therefore, the variance around the average acceleration (a proxy for noise) while fish were stationary was compared statistically ( $F$ test) to data obtained in the mesocosm. As changes in marginal distributions indicate a baseline shift in the tag placement due to physical displacement, a series of statistical meancomparison tests for the average acceleration (Student's $t$ test) were computed within a 10-min moving window for each axis.

\section{Swimming activity}

Steady swimming, defined as dominant tail beat frequency, TBF $(\mathrm{Hz})$, was extracted using a steady-swimming extraction algorithm [11] based on invariant zero-crossing segments $[45,46]$. Absolute swimming speed during steady swimming, $u\left(\mathrm{~ms}^{-1}\right)$ was estimated based on TBF and the empirical relation provided by Long [47] where $u=l(0.005+0.138 \mathrm{TBF})$.

\section{Animal orientation}

Animal orientation (roll angle, $x z, \theta_{R}$ and pitch angle, $\left.z y, \theta_{P}\right)$ was calculated from the static values of the vertical acceleration using Eqs. (1) and (2) below where $x$ is lateral static acceleration, $y$ is forward static acceleration, and $z$ is vertical static acceleration. $\theta$ is the angle of orientation of the tag; i.e. $\overline{\theta_{R}}=\tan ^{-1}\left(\boldsymbol{x}^{\prime} / \boldsymbol{z}^{\prime}\right)$ and $\overline{\theta_{\mathrm{P}}}=\tan ^{-1}\left(\frac{\boldsymbol{y}^{\prime}}{\sqrt{\boldsymbol{x}^{\prime 2}+\boldsymbol{z}^{\prime 2}}}\right)$, where $\boldsymbol{x}^{\prime}$ is average static lateral acceleration, $\boldsymbol{y}^{\prime}$ is the 
average static forward acceleration and $\boldsymbol{z}^{\prime}$ is the average static vertical acceleration. The static acceleration component was calculated by applying a 2 -s moving average to the acceleration time series [48].

$$
\begin{aligned}
& \theta_{R}=\tan ^{-1}\left(\frac{x}{z}\right)-\overline{\theta_{R}} \\
& \theta_{P}=\tan ^{-1}\left(\frac{y}{\sqrt{x^{2}+z^{2}}}\right)-\overline{\theta_{P}}
\end{aligned}
$$

\section{Post-release activity}

Post-release activity was assessed as a function of TBF and burst acceleration movement, which is a proxy for escape response or abnormal behaviour. Burst acceleration movement was extracted using the algorithm outlined in [8]. A proxy for energy expenditure, based on the mean VeDBA [10], given in Eq (3), was estimated for burst acceleration and steady-swimming movement

$$
\mathrm{VeDBA}=\sqrt{A_{x}^{2}+A_{y}^{2}+A_{z}^{2}}
$$

where $A_{x}, A_{y}$ and $A_{z}$ are the absolute dynamic acceleration values for the $x, y$ and $z$ axes, respectively. Dynamic acceleration was calculated by removing the static component from the acceleration time series [48]. Mean VeDBA was calculated for each extracted burst acceleration event.

\section{Behavioural routine}

Behaviour spectra were calculated using the method outlined in Sakamoto et al. [50] by applying a wavelet analysis $($ minimum cycle $=0.04 \mathrm{~s}$, maximum cycle $=80 \mathrm{~s}$ ) with a Morlet mother wavelet function (order 10) applied to lateral acceleration at 1-s intervals. The resulting spectra were clustered using a k-means algorithm to generate ethograms, which correspond to the \% time spent within a distinct behavioural cluster over time (e.g. $[12,49-51])$.

\section{Relation to environmental variables}

Animal behavioural clusters and locomotory activity were assessed in relation to river temperature, depth of fish and ambient light recorded by the PSAT for three fish, and if the length of deployment permitted $(>12 \mathrm{~h})$, to tidal elevation recorded at $1 \mathrm{~min}$ intervals at the Saint John tidal gauge station 65, 45.251W 66.063N (Environment Canada). A wavelet transformation was used on the dominant TBF time series for three individuals $(0.83$, $0.96,1.09 \mathrm{~m} \mathrm{FL}$ ) to examine lower-frequency patterns of activity.

Algorithm computations and statistical analyses were performed using R Studio Statistical Computing Software [52], MATLAB R2014b [53] and IgorPRO 6.3
[54]. All estimates are provided as the average estimate plus or minus one standard deviation unless otherwise noted.

\section{Results}

Average noise level (acceleration variance) measured while the fish were stationary was $0.0002 g_{0}$. This represents the internal tag noise (mechanical, electrical) and was not significantly different to noise from stationary fish in mesocosm studies ( $F$ test, $p>0.05$, [11]). Evidence of tag movement (e.g. complete or partial detachment) during deployments, which typically appears as a shift in average acceleration, was not found since the acceleration average did not change significantly over time (Student's $t$ test, $p>0.05$ for all cases).

\section{Tail beat frequency and associated swimming speed} Weighted density distributions for TBF (Fig. 1) were near log-normal with little variation among sizes and had an average of $1.1 \mathrm{~Hz} \pm 0.47$ with an associated estimated average swimming speed for individuals of $0.14 \mathrm{~ms}^{-1} \pm 0.02$. On average, there were no differences in activity levels (dominant TBF) between day and night (Additional file 3: Fig. S3, Wilcox signed-rank test, $p$ value $>0.05$ ) except for the two smallest individuals where day activity was higher and lower than night activity, respectively (Additional file 3: Fig. S3, Wilcox signed-rank test, $p$ value $<0.05)$.

\section{Animal orientation}

Three fish spent a portion of their time (10-31\%) tilted at absolute pitch angles $\left(y-z\right.$ plane) greater than $10^{\circ}$,

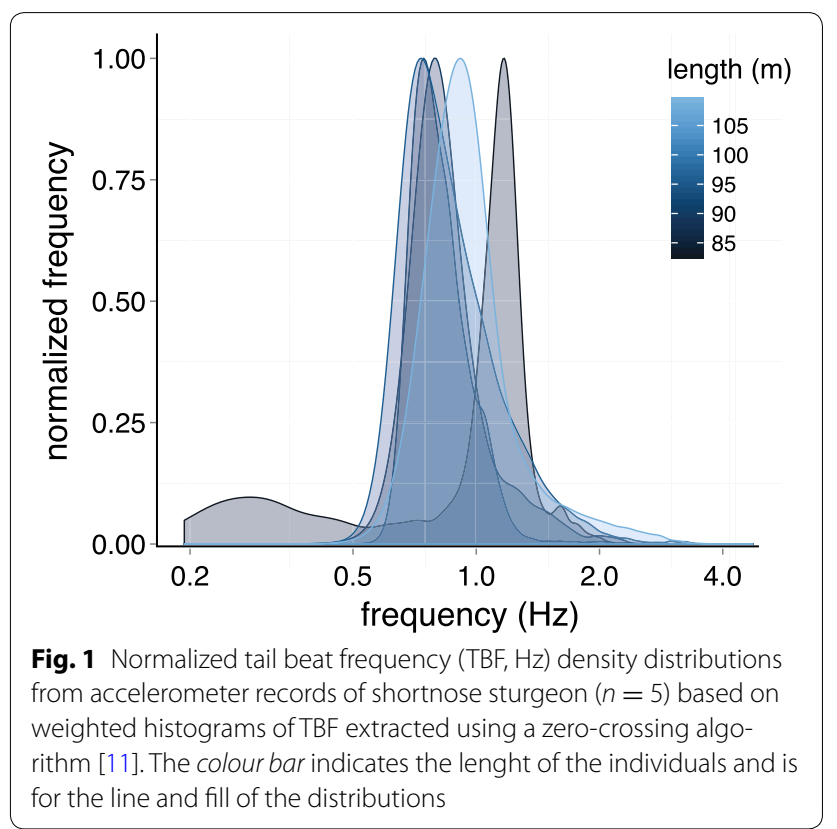


compared to lesser pitch angles $\left(<10^{\circ}\right)$, which are associated with steady swimming (Additional file 4: Fig. S4). The body orientation in the $x-z$ plane (roll) was between $5^{\circ}$ and $10^{\circ}$, though the smallest individual spent considerable time $(30 \%)$ at greater roll angles $\left(\sim 30^{\circ}\right.$, Additional file 4: Fig. S4a). These rolling movements were mostly $(>70 \%)$ on the tag-burden side (left lateral, positive roll).

\section{Post-release behaviour}

Average TBF over short intervals following release was highly variable (Fig. 2). Median TBF was low $(<1 \mathrm{~Hz})$ during the first few hours (Fig. 2). After 7-20 h post-release average TBF tended to stabilize between 0.5 and $1.5 \mathrm{~Hz}$ except for the smallest fish where the average was zero (virtually no swimming) from $12 \mathrm{~h}$ post-release to the time of tag release (Fig. 2a). Extended resting or recovery periods were apparent among all individuals after deployment and ranged from $\sim 2$ (Fig. 3a, d) to $\sim 5 \mathrm{~h}$ (Fig. 3b). For each fish the dominant TBF was $\sim 1 \mathrm{~Hz}$ interspersed with high-frequency burst acceleration. There was no measurable effect of size on recovery period.

The hourly per cent time spent engaging in burst acceleration, which represents abnormal behaviour and escape response, decreased with deployment time (Fig. 4). Overall, burst acceleration was low $(<5 \%$ per hour) and varied little among individuals. One fish exhibited higher burst acceleration rates $\sim 6 \mathrm{~h}$ post-release (Fig. $4 \mathrm{~b}$ ). For all fish, VeDBA during these events was significantly greater than during steady-swimming (TBF) movements $(p<0.01)$ with a twofold to fivefold increase (Fig. 5). For example,

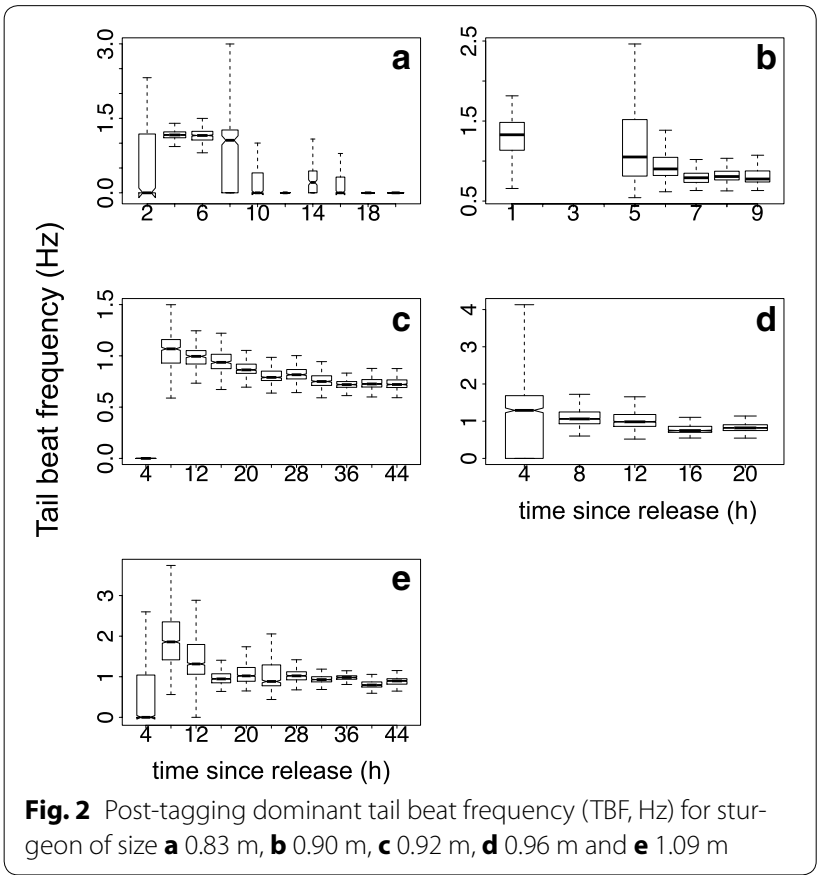

for the largest fish $(1.09 \mathrm{~m})$, the difference was fivefold, and although it engaged in this behaviour $3 \%$ of the total time, the increase in VeDBA and associated energy expenditure during these movements represented a $15 \%$ increase in total VeDBA and likely energy budget.

Behavioural clustering for the five fish (Additional file 5: Fig. S5), based on the behaviour spectrum in Fig. 4, showed that the different fish exhibited different behaviours over the deployment period. The smallest $(0.83 \mathrm{~m})$ fish (Additional file 5: Fig. S5a) showed a resting period of $\sim 1.5 \mathrm{~h}$ followed by $6 \mathrm{~h}$ of unsteady-swimming bouts at $1-1.5 \mathrm{~Hz}$, and low-frequency swaying movements (clusters 1, 2, 3) followed by a 2-h rest period. The 6-h period of unsteady-swimming bouts also coincided with a high roll angle (Additional file 4: Fig. S4), suggesting a tag-removal behaviour ('scouring') or comparable lowfrequency roll movement. The 0.92-m fish (Additional file 5: Fig. S5c) exhibited three distinct steady-swimming clusters $(2,0,1)$ corresponding to $1-3,1$ and $0.7 \mathrm{~Hz}$ 'gaits', respectively, with activity decreasing over time. Cluster 3 was characterized by high-frequency burst acceleration and unsteady swimming that appeared when behaviour switched between gaits. The remaining three fish (0.90, 0.96 and $1.09 \mathrm{~m}$ ) exhibited similar behavioural clusters characterized by varying steady-swimming gaits and high-frequency burst acceleration, mostly observed shortly after release and after the resting period (Additional file 5: Fig. S5b, d, e). For these fish, higherfrequency steady swimming dominated the first $15 \mathrm{~h}$ followed by lower-frequency steady swimming. The two larger fish oscillated between high- and low-frequency gaits with cycle durations of 5-6 h (Additional file 5: Fig. $\mathrm{S} 5 \mathrm{~d}, \mathrm{e})$ for the active post-recovery phase.

\section{Response to environmental variables}

There was no obvious relation between swimming activity (TBF) and depth of the fish and light levels over the deployment period (Additional file 6: Fig. S6). Depth was nearly constant across individuals at $\sim 8 \mathrm{~m}$ for the 0.92 and $0.96 \mathrm{~m}$ fish, $3-5 \mathrm{~m}$ for the largest $(1.09 \mathrm{~m})$ fish, and maximum depth did not exceed $10 \mathrm{~m}$. The two smaller individuals spent their resting period in shallower waters relative to their active phase (Additional file 6: Fig. S6a, b). Similar to depth, ambient light levels were largely constant around $0.4 \mathrm{~V}$ and there was no pattern between time of day and ambient light level, except for one individual (Additional file 6: Fig. S6a) when light level increased markedly around noon without a change in depth. Water temperatures experienced by the fish were relatively constant around $15-16^{\circ} \mathrm{C}$ with some elevation in the afternoon (Additional file 7: Fig. S7).

The response to tidal state (inferred from tidal height at Saint John) differed among individuals. The 0.92-m fish 


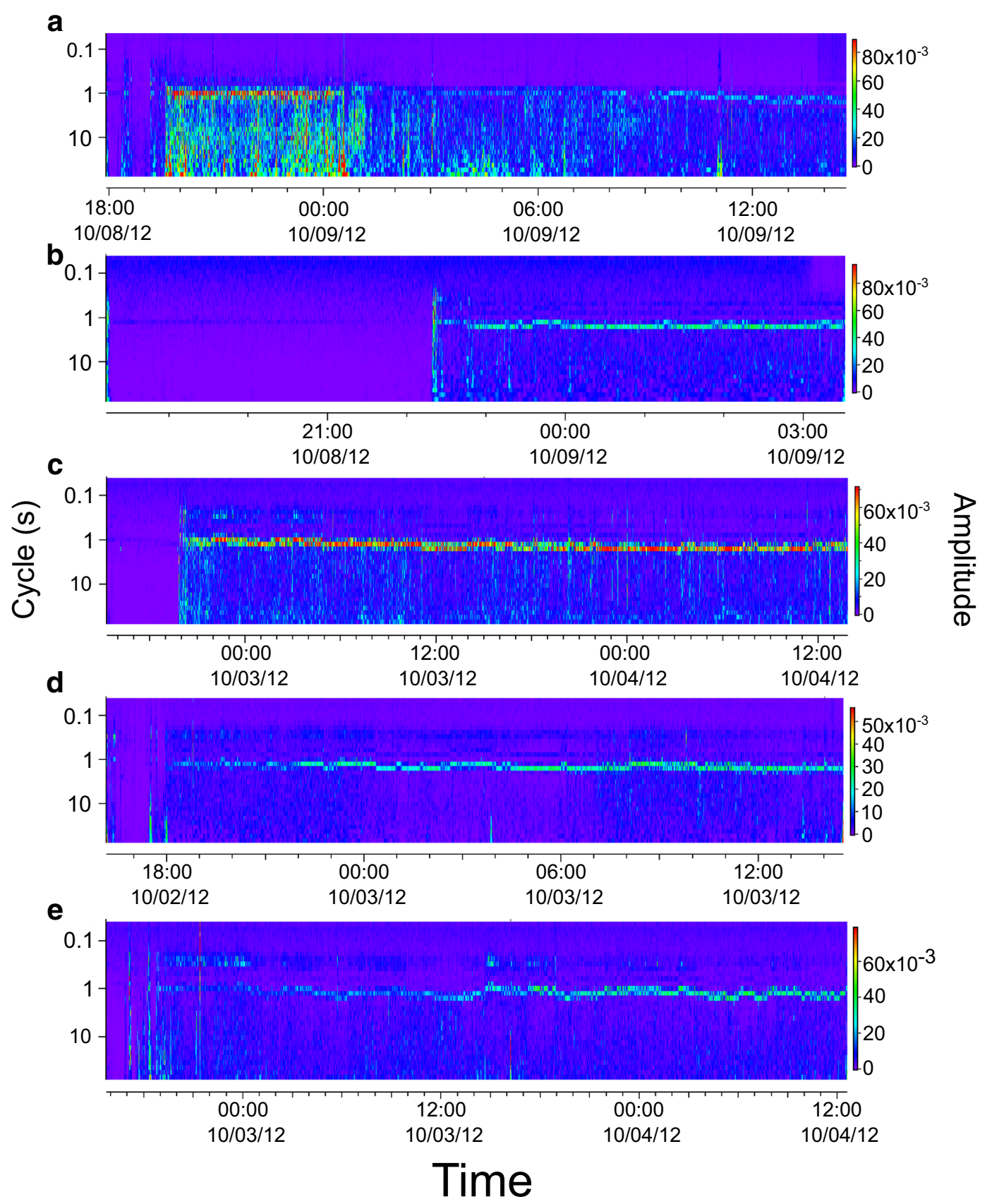

Fig. 3 Behaviour spectrum calculated using a Morelet wavelet transformation based on Sakamoto et al. [50] approach for shortnose sturgeon of length a $0.83 \mathrm{~m}, \mathbf{b} 0.90 \mathrm{~m}, \mathbf{c} 0.92 \mathrm{~m}, \mathbf{d} 0.96 \mathrm{~m}$ and $\mathbf{e} 1.09 \mathrm{~m}$. The tail beat frequency cycles are in seconds, and the colour shows the amplitude of the frequency for every second for each fish

(Fig. 6b) decreased its activity levels (TBF) with high tide; however, the decreases were small $(1.2-0.9 \mathrm{~Hz}$, and 0.9$0.8 \mathrm{~Hz}$ ). The smallest individual (Fig. 6) exhibited higher activity during low tide (20:00-02:00) and decreased activity during high tide (02:00-08:00). Similar to the cluster analysis, for fish 0.96 and $1.09 \mathrm{~m}$, a wavelet analysis of TBF revealed an oscillation in the activity (TBF) series corresponding to $4.4-5 \mathrm{~h}(0.96 \mathrm{~m})$ and $6.1 \mathrm{~h}(1.09 \mathrm{~m})$ (Fig. $7 \mathrm{~b}$, c); however, we were not able to determine whether these oscillations were related to the semi-diurnal tide (Fig. 6). 

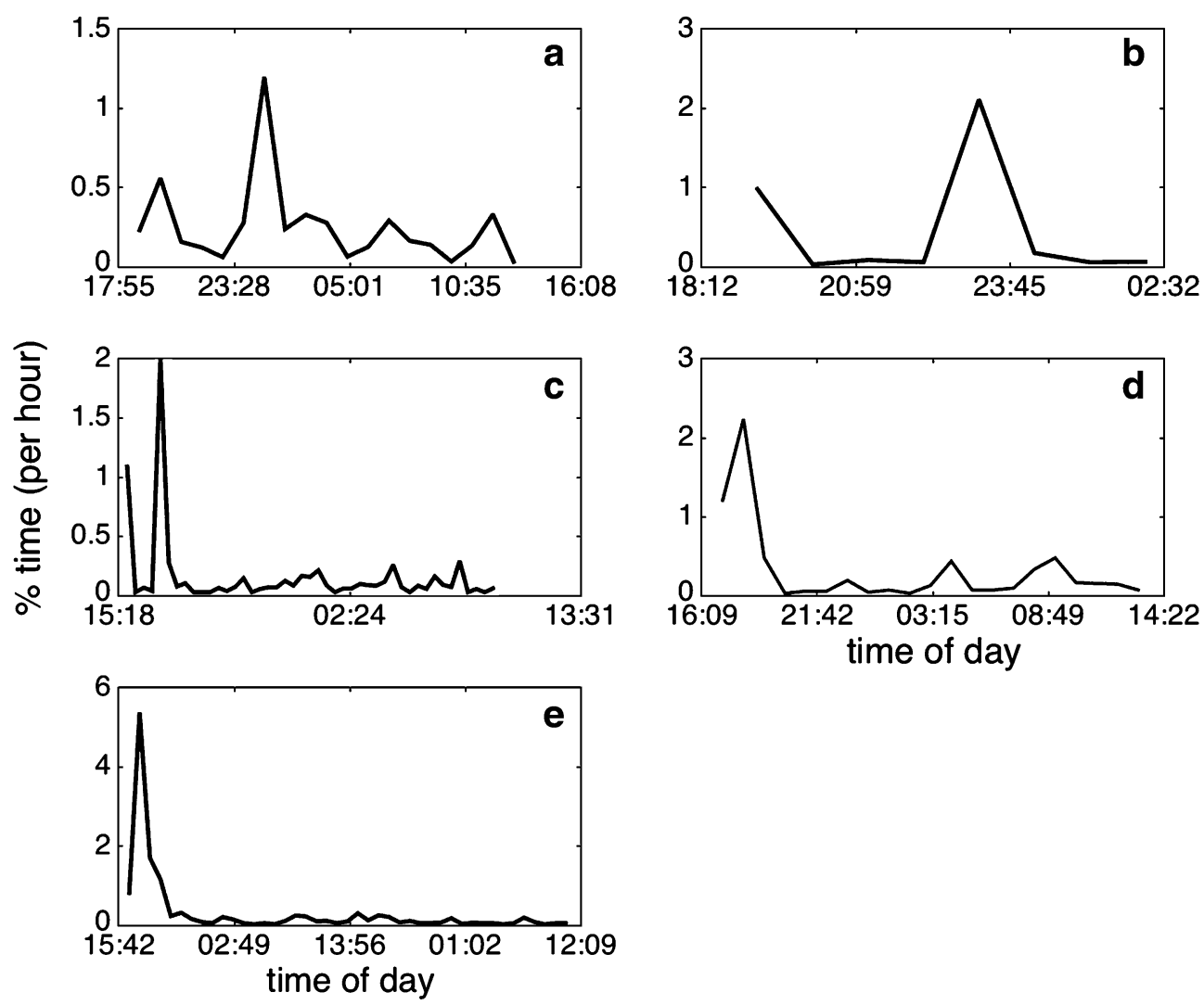

Fig. 4 Per cent time (per hour) spent by the five sturgeons of length $\mathbf{a} 0.83 \mathrm{~m}, \mathbf{b} 0.90 \mathrm{~m}, \mathbf{c} 0.92 \mathrm{~m}, \mathbf{d} 0.96 \mathrm{~m}$ and e $1.09 \mathrm{~m}$, engaging in burst acceleration movements as a function of time (in hours)

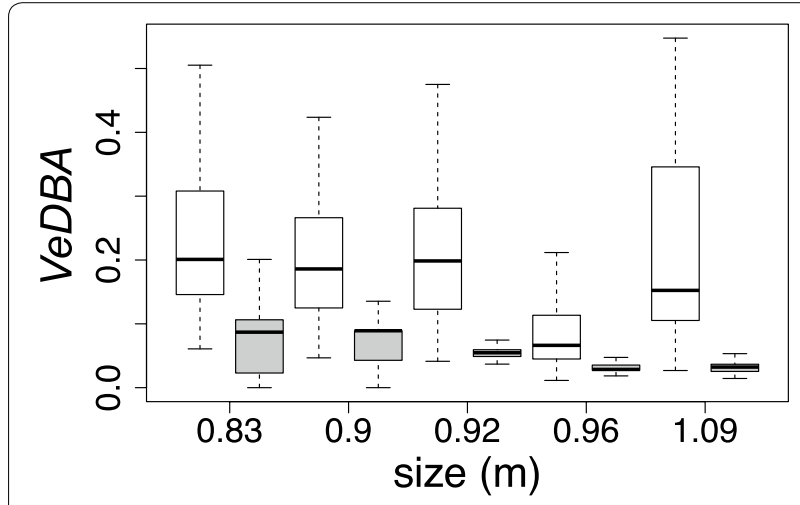

Fig. 5 Boxplots of the energy expenditure proxy, VeDBA, as a function of sturgeon length $(\mathrm{m})$ during routine behaviour (grey), burst acceleration movements (white). VeDBA was calculated from burst acceleration movements (Eq. 3; [10])

\section{Discussion}

We have developed a secure, rigid, two-point attachment method for a single-point release PSAT and acceleration tag. We were able to retrieve the tags in the wild using acoustic telemetry and recovered high-frequency $(50 \mathrm{~Hz})$ acceleration data for quantifying swimming activity and speed, post-tagging behavioural responses and their relations to the ambient environment.

\section{Tag attachment}

Given that accelerometer noise levels were similar to data collected in a mesocosm study [11], and that marginal data distributions were constant, we are confident the tag mount was secure. While the tag attachment was specifically designed for sturgeon, it could be adjusted for use with other species since Petersen discs have been successfully used for decades [55]. For longer-term studies, this method will likely require modifications since dissolvable sutures were used and the multiple components may be prone to biofouling. One solution could be a cradle that houses the tag and contains a built-in release mechanism. This would provide the secure attachment needed by the acceleration sensor and could provide for reduced drag relative to the conventional single-point PSAT attachments [24].

\section{Post-release behaviour}

All tagged sturgeons exhibited extended resting periods after release $(2-5 \mathrm{~h})$ characterized by a low TBF. During 


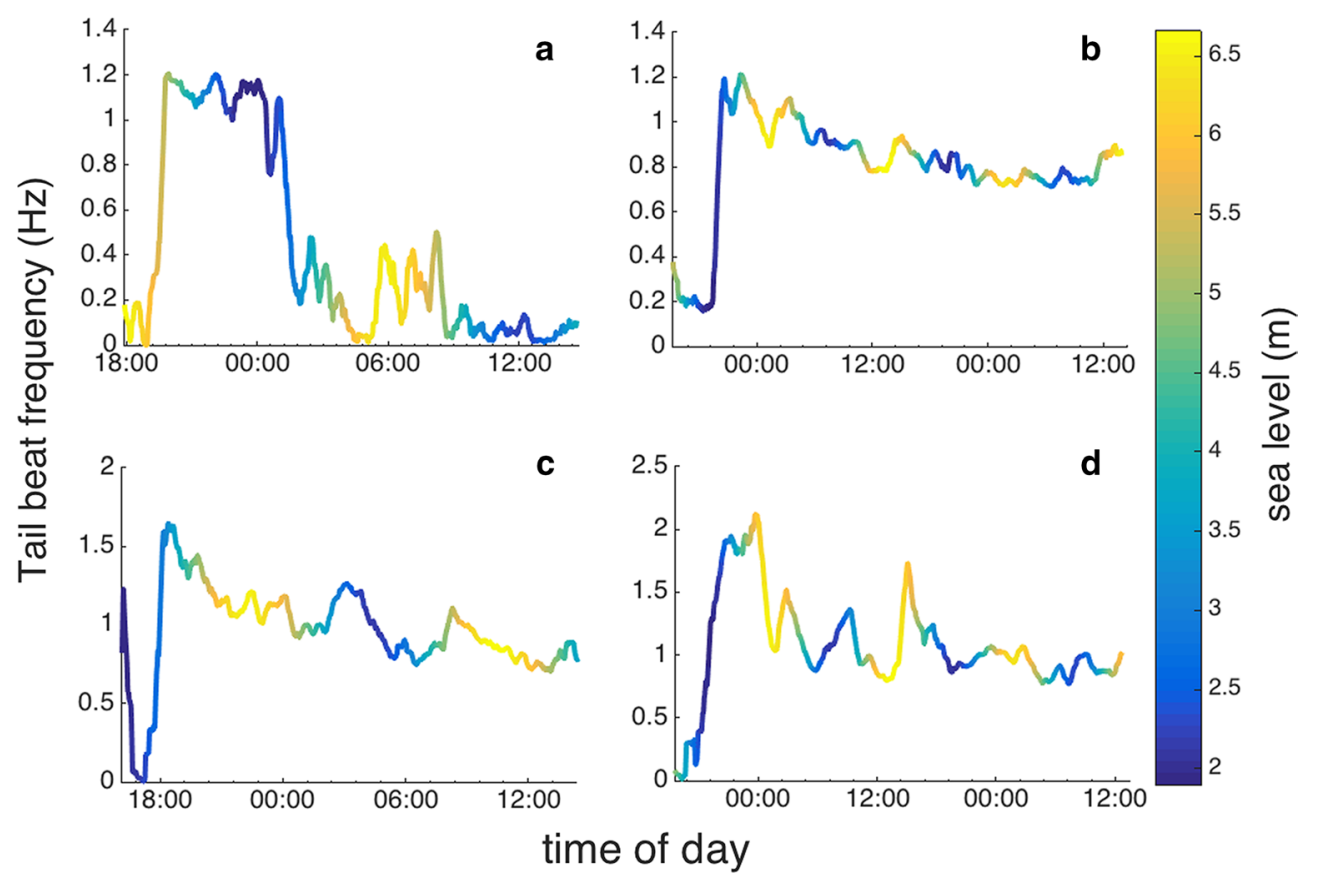

Fig. 6 Time series of dominant tail beat frequency $(T B F, H z)$ as a function of sea level $(\mathrm{m})$ for four sturgeons of length a $0.83 \mathrm{~m}, \mathbf{b} 0.92 \mathrm{~m}, \mathbf{c} 0.96 \mathrm{~m}$ and $\mathbf{d} 1.09 \mathrm{~m}$

resting periods, fish were likely holding station on the river bed, which can function as an energy saving strategy [56]. Holding station against a downstream current can be achieved by flow-refuging [57] or by taking advantage of the flattened body morphology by pressing the body and pectoral fins against the substrate as has been observed in flume studies for various sturgeon species [57-59]. While this has been considered a mechanism for refuge from high flow, it may also function as a compensatory mechanism for recovery from post-handling stress. During the resting phase, the fish exhibited short time-scale burst acceleration events characterized by high maximum accelerations of up to $5 g_{0}$. Since these events occur most frequently just post-release, they most likely relate to tagging stress or tag-load-removing behaviour (e.g. [60, 61]), and given the high VeDBA, they considerably affect the total energy budget. High VeDBA during tag-load-related movements, indicated by high roll angles in the smallest individual, likely contributed to additional energy expenditure. The extended resting period and increased energy expenditure due to postrelease stress could contribute to increased vulnerability to other stressors, fishing recapture or death $[30,31,40$, $41,59,62-65]$.

Following the resting period, the activity levels of the sturgeon, measured as TBF, remained fairly constant across fish in the $0.5-1.5 \mathrm{~Hz}$ range. Yet, the smallest individual exhibited unsteady-swimming activity and station holding throughout the deployment period. Additionally, this individual displayed movement associated with rolling behaviour during the first $10 \mathrm{~h}$ of deployment (time series of roll angle, not presented here). This may relate to tag-removal behaviour similar to the scouring movement in Atlantic cod [60] and has also been observed in shortnose sturgeon in response to tag load [61]. This too suggests a considerable impact of tagging, handling and tag-load ( $>2 \%)$ stresses and questions the health status and long-term survival of the individual. Clearly, longer deployment periods are needed to assess the impact of tagging procedures on sturgeons. Our study suggests the potential for using accelerometer tags to evaluate the impact of capture and tagging protocols. This information is key to the interpretation of movement and behaviours from tags of all types.

Behavioural changes similar to the responses observed here have been related to the physiological and biochemical effects of exhaustive exercise associated with capture and handling [28-30] along with blood acidosis and high blood lactate levels that have been reported for tuna, sharks and billfish subjected to and exhaustive exercise due to capture and handling stress [31, 33]. Long capture periods, as observed here, may lead to hypoxia, and size may affect in the ability of a fish to withstand capture, handling and tag load similar to other species (e.g. [28]). For example, juvenile shortnose sturgeons exhibit a physiological stress response to physical disturbances 

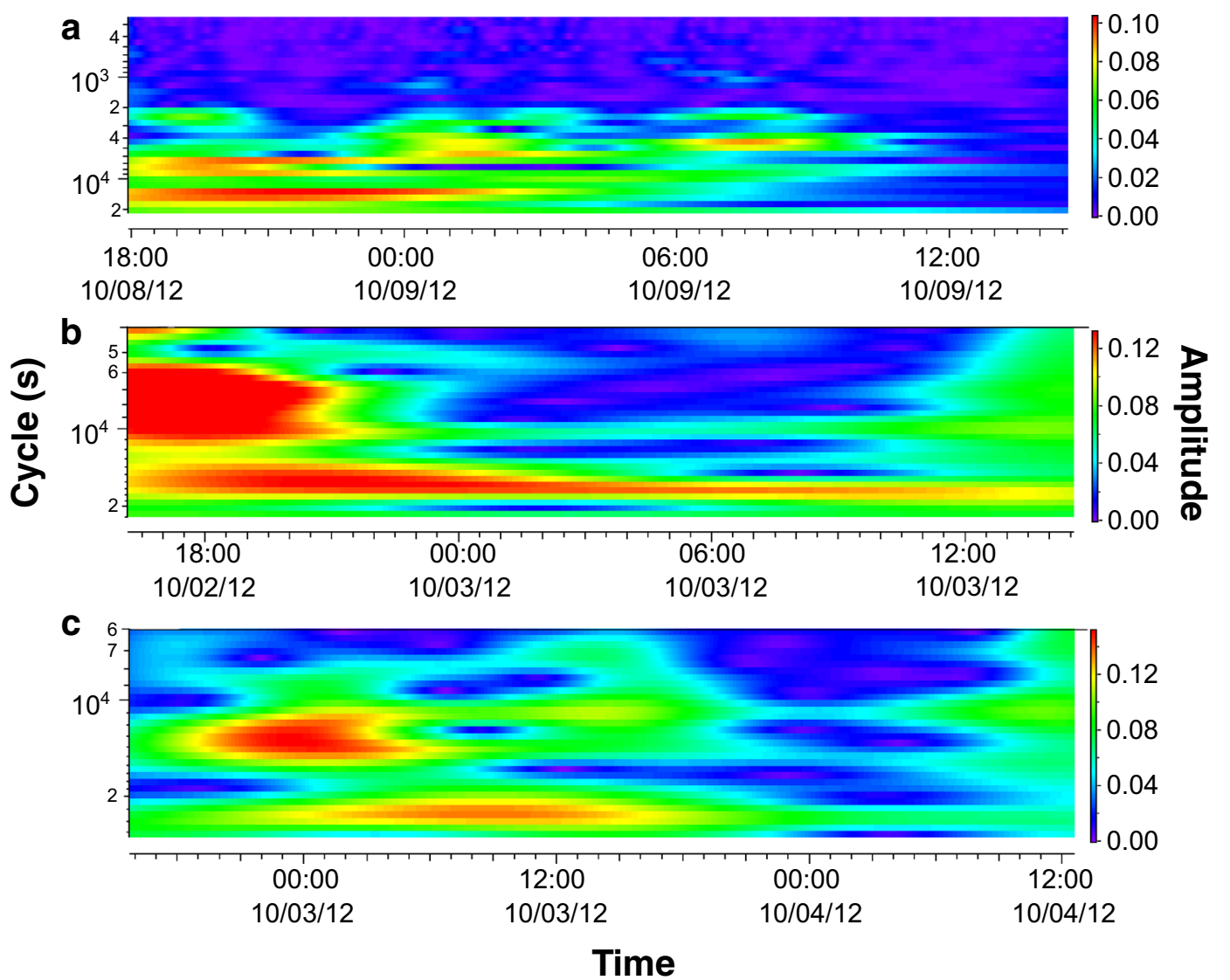

Fig. 7 Wavelet transformation of dominant TBF extracted from the zero-crossing algorithm represented as cycle (s) as a function of time of day for three sturgeons of length $\mathbf{a} 83 \mathrm{~cm}, \mathbf{b} 96 \mathrm{~cm}$ and $\mathbf{c} 109 \mathrm{~cm}$ where the colour coding corresponds to the amplitude of the wavelet transform

(chasing) in the laboratory, as indicated by changes in whole-body oxygen consumption, ammonia excretion rates and changes in the levels of muscle and blood metabolites [62]. However, the physiological responses of shortnose sturgeon to chasing were muted relative to other teleost fish species suggesting that shortnose sturgeons respond differently than other popularly angled teleost fishes such as salmonids and centrachids and shortnose sturgeon appear to recover rapidly (6 h) [62]. While drawing inferences from captive hatchery-reared fish is problematic (e.g. [64]), if a similar mechanism exists in adults, recovery is expected in less than $6 \mathrm{~h}$ for all physiological variable measured (except for glucose) which could potentially explain the duration of the recovery phase observed here (up to $5 \mathrm{~h}$ ) and suggests that physiological metabolites will normalize within the time period of the study.

A further possibility is that the behavioural modifications observed in these animals were affected by other factors such as temperature, foraging, predator evasion or bathymetry which cannot be excluded. However, given that the recovery response is similar across individuals, the behavioural response to tagging and release may be simply due to tag effect and tag load (e.g. [14, 27, 66]).

\section{Swimming speed and behavioural clusters}

Shortnose sturgeon exhibited significantly lower average TBF $(\sim 1 \mathrm{~Hz})$ and associated swimming speeds $\left(<0.2 \mathrm{~ms}^{-1}\right.$ or $\left.<0.2 \mathrm{BLs}^{-1}\right)$ than those observed in laboratory studies [67-70]. The high pitch angles $\left(>10^{\circ}\right)$ that were observed $>50 \%$ of the time among all fish may be related to low river-flow speeds of $<1 \mathrm{BLs}^{-1}$ when the negatively buoyant fish swim at unsteady rates or to achieve a force balance when swimming in the low current [69]. Given that the low swimming speeds were relatively constant over the 2-day deployment, and assuming they are unrelated to post-release stress, this suggests that in the wild sturgeon do not typically exhibit high swimming speeds $>1 \mathrm{BLs}^{-1}$. For example, adult lake sturgeon, Acipenser fulvescens (1.20-1.34 $\mathrm{m}$ total length), were observed to swim at $0.3 \mathrm{BLs}^{-1}$ during steady swimming in a still water tank [47] and displayed two distinct gaits of locomotion, 
a 'slow' mode of $0.1 \mathrm{BLs}^{-1}$ and a 'fast' mode of $0.25 \mathrm{BLs}^{-1}$. We also found evidence of a gait-switching mechanism: for example, the largest individual $(1.09 \mathrm{~m})$ spent close to $100 \%$ of the time at two gaits, at $0.83 \mathrm{~Hz}\left(0.12 \mathrm{BLs}^{-1}\right)$ and $1.1 \mathrm{~Hz}\left(0.16 \mathrm{BLs}^{-1}\right)$. Large-scale behavioural gaits have previously been observed in shortnose sturgeon [32] and in Chinese sturgeon (Acipenser sinensis) that exhibited low dominant TBF and associated swimming speeds $\left(<1 \mathrm{BLs}^{-1},[71]\right)$ that are similar to the estimates reported here. All of the above further suggest a discrepancy between free-swimming wild-fish estimates relative to laboratory estimates (e.g. [67, 69]). Most kinematic studies are conducted in flume tanks to simulate dam passage and rarely include swimming at low speeds (e.g. [67-70]). One potential explanation is that endurance during lower swimming speeds is elevated as suggested by studies on juvenile sturgeon [56]. Recent observations for swordfish also indicate considerably lower swimming speeds in the wild than hypothesized [72]. We therefore suggest a reexamination of swimming efficiencies in relation to lower speeds in kinematic and energetic studies, since fish in the wild may be adopting speeds much lower than those predicted from flume studies.

\section{Behavioural routines}

Overall, sturgeon did not exhibit any clear diurnal activity patterns (e.g. TBF) likely because they modulate their swimming activity in relation to river flow as suggested for other sturgeon [57]. All fish exhibited a combination of two or more steady-swimming gaits, and for two fish, these gaits appeared to change every 4-6 h, though the time series was short $(\sim 48 \mathrm{~h})$. These behavioural oscillations may be due to a tidally influenced current as the tidal phase has a measureable effect on the Kennebecasis River during the spring tide [43] that coincided with the deployment period in the study and was noticeable at the study site (personal observation). Using the Saint John weather buoy to extrapolate timing of high and low tide, however, is difficult, since the lag between the locations ( $\sim 40 \mathrm{~km}$ up river) is unknown and may be considerable (>hours). Tidal flow has been observed to affect swimming speed in shortnose sturgeon [32] and other species $[73,74]$ with fish moving with the ebb and against the flood tides. Therefore it is expected that fish activity during station holding or upstream movement would be related to some phase of tide. The gait change in the two largest fish may correspond to an activity response in relation to tidal flow, especially the variation in activity with a near semi-diurnal oscillation $(\sim 6 \mathrm{~h})$ as illustrated in Figs. $6 \mathrm{c}, \mathrm{d}$ and $7 \mathrm{~b}, \mathrm{c}$. Given the small variability in light, temperature and depth, these individuals may have been station holding at depth throughout most of the deployment and therefore may have modulated their TBF with the tidal flow. However, due to the potential lag between the time series, it is difficult to relate these observations to the timing of the tide.

All individuals likely spent most of the study period in the upper shallower ranges of the Kennebecasis River, since they all inhabited depth levels $<10 \mathrm{~m}$ and Kennebecasis Bay is characterized by median depths of $\sim 20 \mathrm{~m}[42$, 43]. This also implies that the individuals did not move far from the release site, confirmed by the tag pop-up locations that were between 2 and $5 \mathrm{~km}$ from the release site, similar to observations for other sturgeon [57]. Differences in depth and light levels among individuals indicate difference in the habitat used or different recovery strategies (relocation from release site vs. recovery by station holding at constant depth close to release site). The two individuals that spent most of their time at constant (low) ambient light likely used habitats closer to the riverbanks in the upper parts of the river that is dominated by river grasses and marsh banks. Similar observations suggest that sturgeons stay in habitats where velocities would remain relatively low [57]. Variability in ambient light was only observed for one individual $(0.92 \mathrm{~m})$. This fish may have inhabited the streambed where the water is clearer or areas along the riverbanks downstream where marsh-land density is lower.

\section{Conclusions}

In summary, most of the behavioural routines exhibited by the tagged sturgeon appeared to be related to posttagging effects and the activities were largely characterized by modulations in the swimming gait. While the ethogram analysis was able to group the acceleration signals into distinct behavioural clusters, without visual validation of behaviour and acceleration data, it remains challenging to directly qualify these clusters in relation to distinct behaviour. For example, these gaits may correspond to swimming versus feeding or searching for food, or different environments such as lower versus higher river flow.

Our study illustrates the difficulty in relating movement and activity to environmental patterns or habitat. This is particularly challenging with short-duration deployments (days) due to the apparent tagging and handling effects on behaviour. Given the short deployment period, it is difficult to quantify the total extent of the recovery (resting and post-release behaviour modification) period for these fish because there are no baseline measurements of high-resolution movement and activity. The post-release resting phase is likely comparable to a recovery state due to physiological stress (e.g. [62]), and it may take more time (days to weeks) before 
behaviour and movement returns to a more steadyswimming state. However, if we assume that TBF and swimming speed from the mesocosm studies [11] are the baseline for this species, then only the two largest individual exhibited TBF and swimming speeds similar or close to predictions and therefore could be considered as 'normal' movement and activity as it corresponds to activity in fish that were not stressed [11]. Therefore, making predictions on swimming speed and general activity based on a short tag deployment period (e.g. [72]) could lead to compromised estimates that are affected by post-release stresses.

We expect that behavioural modifications in response to tagging and handling are likely related to the tagging surgery, which was long (as much as $15 \mathrm{~min}$ ) and without an anaesthetic, as well as the long holding time ( $>1$ day) prior to tag attachment. Additionally, tag load may have an effect on animal behaviour (3\% for the smallest individual) as indicated by evidence of rolling movements similar to tag response in Atlantic cod [60]. It is now commonly acknowledged that devices attached to animals may have adverse effects on their behaviour, as well as individual fitness, and directly or indirectly affect performance [75]. While the tag attachment delivered nearly noise-free acceleration signals, the considerable impact on post-release stress suggests that the surgery and attachment protocols require improvements.

For future studies, longer time series of activity (acceleration) using a less invasive attachment method suitable for longer duration studies should allow for the identification of routine behaviours that are not affected by post-tagging stress. Initially, this will require a longerterm tagging trial in a controlled environment. Shortterm behavioural adjustment post-release should be combined with physiological measurements (e.g. blood and muscle metabolites) as well as control animals to allow for behavioural comparisons. Such information could then be used to assess behaviour response in the context to physiological response to a catch-and-release fishery. The above results clearly indicate that it is challenging to infer animal behaviour and movement based on a short time series that is exacerbated by post-release stress.

\section{Additional files}

Additional file 1: Figure S1. Map of the Kennebecasis River, New Brunswick, Canada study area (adapted from [76]). The solid rectangle A indicates study area and the small red rectangle the sturgeon release point.

Additional file 2: Figure S2. Illustration of pop-up satellite tag attachment to shortnose sturgeon using a longitudinal, dorsal, two-point anchor. The black cylinder represents $\mathrm{V} 9$ transmitter and the grey cylinder the MBLog PT-1 accelerometer.
Additional file 3: Figure S3. Normalized tail beat frequency $(\mathrm{TBF}, \mathrm{Hz})$ density distributions from accelerometer records of shortnose sturgeon $(n=5)$ based on weighted histograms of TBF extracted using the zero-crossing algorithm for day (blue) and night (black) for fish of length (a) $0.83 \mathrm{~m}$, (b) $0.90 \mathrm{~m}$, (c) $0.92 \mathrm{~m}$, (d) $0.96 \mathrm{~m}$, (e) $1.09 \mathrm{~m}$, and (f) all fish combined.

Additional file 4: Figure S4. Normalized histogram for pitch angle $\left(^{\circ}\right)$ in the $y-z$ plane (left panel) and for yaw angle $\left(^{\circ}\right)$ in the $x$-y plane for fish of length (a) $0.83 \mathrm{~m}$, (b) $0.90 \mathrm{~m}$, (c) $0.92 \mathrm{~m}$, (d) $0.96 \mathrm{~m}$, and (e) $1.09 \mathrm{~m}$.

Additional file 5: Figure S5. Behavioural clustering for the five sturgeon (a to e; smallest to largest respectively) illustrating (i) the four elements of the acceleration ethogram based on the behaviour spectra in Fig. 7 where the vertical axis represents the amplitude of acceleration, the horizontal axis represents the cycle length of the acceleration, (ii) the percent of time spent in each cluster, and (iii) the time series of \% times assigned to each cluster over deployment time. Colour coding corresponds to behavioural clusters in (i).

Additional file 6: Figure S6. Dominant tail beat frequency $(T B F, H z)$ as a function of time and depth $(\mathrm{m})$ and ambient light level (solar $\mathrm{V}$ ) for three sturgeon of length a) $0.92 \mathrm{~m}$, b) $0.96 \mathrm{~m}$ and c) $1.09 \mathrm{~m}$.

Additional file 7: Figure S7. Time series of ambient temperature $\left({ }^{\circ} \mathrm{C}\right)$ during deployment for three sturgeon of length a) $0.92 \mathrm{~m}$, b) $0.96 \mathrm{~m}$, and c) $1.09 \mathrm{~m}$.

\section{List of symbols}

$A_{x}, A_{y}, A_{z}$ : absolute dynamic acceleration values for $x, y$ and $z$ axes, respectively; $\mathrm{FL}$ : fork length (m); l: length (m); $m$ : mass (kg); $n$ : sample size; TBF: tail beat frequency $(\mathrm{Hz}) ; \mathrm{TL}$ : total length $(\mathrm{m})$; $u$ : estimated swimming speed $\left(\mathrm{ms}^{-1}\right)$; VeDBA: vectorial dynamic body acceleration; $x$ : $x$-axis acceleration (lateral); $y$ : $y$-axis acceleration (forward); $z$ : $z$-axis acceleration (vertical); $\theta$ : tag angle orientation; $\theta_{p}$ : pitch angle; $\theta_{R}$ : roll angle.

\section{Authors' contributions}

All authors designed the experimental study and collected the data. AB designed the accelerometer tag used in the study. MKL designed the tag attachment methods with insights from FB, AT and CTT. FB conducted the data analysis and manuscript preparation with insights and interpretation from CTT. All authors provided critiques on the research and contributed to the manuscript. All authors read and approved the final manuscript.

\section{Author details}

${ }^{1}$ Oceanography Department, Dalhousie University, 1355 Oxford Street, Halifax B3H 4R2, Canada. ${ }^{2}$ Biology Department, Mount Allison University, Sackville, NB E4L 1E4, Canada. ${ }^{3}$ School of Biomedical Engineering, Dalhousie University, Halifax, NS B3H 4R2, Canada.

\section{Acknowledgements}

We thank J.-P. Auclair for insights and discussions on data processing. We also like to thank the recreational catch-and-release fishermen for providing the shortnose sturgeon used in this study. We thank Bill Cameron for help in the design of the tag attachment method.

\section{Competing interests}

The authors declare that they have no competing interests.

\section{Ethics approval}

Fish care and protocols for fish holding, surgery and tagging were approved by Mount Allison University (sturgeon, Permit 10-16) in accordance with the Canadian Council for Animal Care standards.

\section{Funding}

This work was supported by funding for two collaborating projects (MKL, ADT) and (CTT, FB, AB) within the Ocean Tracking Network (OTN) through a network project grant [NETGP 375118-08] from the Canadian Natural Sciences and Engineering research Council (NSERC) and with additional support from the Canadian Foundation for Innovation (CFI, Project \#13011). Funding was also provided to MKL through an NSERC Discovery grant a New Brunswick Wildlife Fund grant. 
Received: 14 December 2015 Accepted: 3 April 2016 Published online: 29 April 2016

\section{References}

1. Cooke SJ, Hinch SG, Wikelski M, Andrews RD, Kuchel LJ, Wolcott TG, Butler PJ. Biotelemetry: a mechanistic approach to ecology. Trends Ecol Evol. 2004;19:334-43. doi:10.1016/j.tree.2004.04.003.

2. Preston TJ, Chiaradia A, Caarels SA, Reina RD. Fine scale biologging of an inshore marine animal. J Exp Mar Bio Ecol. 2010;390:196-202.

3. Bograd SJ, Block BA, Costa DP, Godley BJ. Biologging technologies: new tools for conservation. Introduction. Endang Species Res. 2010;10:1-7.

4. Kawabe R, Nashimoto K, Hiraishi T, Naito Y, Sato K. A new device for monitoring the activity of freely swimming flatfish, Japanese flounder Paralichthys olivaceus. Fish Sci. 2003;69:3-10. doi:10.1016/j.icesjms.2004.07.014.

5. Kawabe R, Kawano T, Nakano N, Yamashita N, Hiraishi T, Naito Y. Simultaneous measurement of swimming speed and tail beat activity of free swimming rainbow trout Oncorhynchus mykiss using an acceleration data-logger. Fish Sci. 2003;69:959-65. doi:10.1046/j.1444-2906.2003.00713.x.

6. Tsuda Y, Kawabe R, Tanaka H, Mitsunaga Y, Hiraishi T, Yamamoto K, Nashimoto K. Monitoring the spawning behavior of chum salmon with an acceleration data logger. Ecol Freshw Fish. 2006;15:264-74. doi:10.1111/j.1600-0633.2006.00147.x.

7. Gleiss AC, Norman B, Liebsch N, Francis C, Wilson RP. A new prospect for tagging large free-swimming sharks with motion-sensitive data-loggers. Fish Res. 2009;98:16-22. doi:10.1016/j.fishres.2008.12.012.

8. Broell F, Noda T, Wright S, Domenici P, Steffensen JF, Auclair J-P, Taggart CT. Accelerometer tags: detecting and identifying activities in fish and the effect of sampling frequency. J Exp Biol. 2013;216:1255-64. doi:10.1242/jeb.077396

9. Noda T, Kawabata Y, Arai N, Mitamura H, Watanabe S. Animal-mounted gyroscope/accelerometer/magnetometer: in situ measurement of the movement performance of fast-start behaviour in fish. J Exp Mar Biol Ecol. 2014;451:55-68. doi:10.1016/j.jembe.2013.10.031.

10. Wright S, Metcalfe JD, Hetherington S, Wilson R. Estimating activityspecific energy expenditure in teleost fish, using accelerometer loggers. Mar Ecol Prog Ser. 2014;496:19-32. doi:10.3354/meps10528.

11. Broell F, Taggart CT. Scaling in free-swimming fish and implications for measuring size-at-time in the wild. PLoS One. 2015;10(12):e0144875.

12. Whitney N, Pratt HL, Pratt TC, Carrier JC. Identifying shark mating behaviour using three-dimensional acceleration loggers. Endang Species Res. 2010:10:71-82. doi:10.3354/esr00247.

13. Carroll G, Slip D, Jonsen I, Harcourt R. Supervised accelerometry analysis can identify prey capture by penguins at sea. J Exp Biol. 2014;217:4295302. doi:10.1242/jeb.113076.

14. Musyl MK, Domeier ML, Nasby-Lucas N, Brill RW, McNaughton LM, Swimmer JY, Lutcavage MS, Wilson SG, Galuardi B, Liddle JB. Performance of pop-up satellite archival tags. Mar Ecol Prog Ser. 2001;433:1-28. doi:10.3354/meps09202.

15. Fedak M, Lovell P, McConnell B, Hunter C. Overcoming the constraints of long range radio telemetry from animals: getting more useful data from smaller packages. Integr Comp Biol. 2002;42:3-10. doi:10.1093/icb/42.1.3.

16. Block BA, Dewar $H$, Farwell C, Prince ED. A new satellite technology for tracking the movements of Atlantic bluefin tuna. Proc Natl Acad Sci USA. 1998:95:9384-9.

17. Campana SE, Dorey A, Fowler M, Joyce W, Wang Z, Wright D. Migration pathways, behavioural thermoregulation and overwintering grounds of blue sharks in the Northwest Atlantic. PLoS One. 2011;6(2):e16854. doi:10.1371/journal.pone.0016854.

18. Armsworthy SL, Trzcinski MK, Campana SE. Movements, environmental associations, and presumed spawning locations of Atlantic halibut (Hippoglossus hippoglossus) in the northwest Atlantic determined using archival satellite pop-up tags. Mar Biol. 2014;161:645-56. doi:10.1007/ s00227-013-2367-5.

19. Block BA, Dewar H, Blackwell SB, Williams TD, Prince ED, Farwell CJ, Boustany A, Teo SH, Seitz A, Walli Fudge D. Migratory movements, depth preferences, and thermal biology of Atlantic bluefin tuna. Science. 2001:293:1310-4. doi:10.1126/science.1061197.
20. Chaprales W, Lutcavage M, Brill R, Chase B, Skomal G. Harpoon method for attaching ultrasonic and 'popup' satellite tags to giant bluefin tuna and large pelagic fishes. Mar Technol Soc J. 1998;32:104-5.

21. Lutcavage M, Rhodin AGJ, Sandove SS. Conroy CR Direct carapacial attachment of satellite tags using orthopedic bioabsorbable mini-anchor screws on leatherback turtles in Culebra. Puerto Rico Mar Turtle Newsl. 2001;95:9-12.

22. Swimmer Y, Brill R, Musyl M. Use of pop-up satellite archival tags to quantify mortality in marine turtles incidentally captured in longline fishing gear. Mar Turtle Newsl. 2002;97:3-7.

23. Prince ED, Ortiz M, Venizelos A, Rosenthal DS. In-water conventional tagging techniques developed by the cooperative tagging center for large, highly migratory species. In: Lucy JA, Studholme AL, editors. Catch and release in marine recreational fisheries. American Fisheries Society Symposia: Bethesda; 2002. p. 155-71.

24. Methling C, Tudorache C, Skov PV, Steffensen JF. Pop up satellite tags impair swimming performance and energetics of the European eel (Anguilla anguilla). PLoS One. 2001;6:e20797. doi:10.1371/journal. pone.0020797.

25. Payne NL, Taylor MD, Watanabe YY, Semmens JM. From physiology to physics: are we recognizing the flexibility of biologging tools? J Exp Biol. 2014:217:317-22. doi:10.1242/jeb.093922.

26. Chapple TK, Gleiss AC, Jewell OJD, Wikelski M, Block BA. Tracking sharks without teeth: a non-invasive rigid tag attachment for large predatory sharks. Anim Biotelem. 2015;3:14. doi:10.1186/s40317-015-0044-9.

27. Bridger CJ, Booth RK. The effects of biotelemetry transmitter presence and attachment procedures on fish physiology and behavior. Rev Fish Sci. 2003;11:13-34. doi:10.1080/16226510390856510.

28. Hoolihan JP, Luo J, Abascal FJ, Campana SE, De Metrio G, Dewar H, Domeier ML, Howey LA, Lutcavage ME, Musyl MK, Neilson JD, Orbesen ES, Prince ED, Rooker JR. Evaluating post-release behaviour modification in large pelagic fish deployed with pop-up satellite archival tags. ICES J Mar Sci. 2011:68:880-9. doi:10.1093/icesjms/fsr024.

29. Wells RMG, Mclntyre RH, Morgan AK, Davie PS. Physiological stress responses in big gamefish after capture: observations on plasma chemistry and blood factors. Comp Biochem Physiol. 1986;84:565-71.

30. Skomal GB, Chase BC. The physiological effects of angling on post-release survivorship in tunas, sharks, and marlin. In: Lucy JA, Studholme AL, editors. Catch and release in marine recreational fisheries, 5-8 December 1999, Virginia Beach. Bethesda: American Fisheries Society Symposium; 2002. p. 135-8.

31. Wells RMG, Davie PS. Oxygen binding by the blood and hematological effects of capture stress in two big gamefish: Mako shark and striped marlin. Comp Biochem Physiol. 1985;81:643-6.

32. McLeave JD, Fried SM, Towt AK. Daily movements of shortnose sturgeon, Acipenser brevirostrum, in a Maine estuary. Copeia. 1977;1:149-57.

33. Skomal GB. Evaluating the physiological and physical consequences of capture on post-release survivorship in large pelagic fishes. Fish Manag Ecol. 2007;14:81-9.

34. Dadswell MJ. Biology and population characteristics of the shortnose sturgeon, Acipenser brevirostrum, LeSueur 1818 (Osteichthyes:Acipenseridae), in the Saint John River Estuary, New Brunswick, Canada. Can J Zool. 1818;19779(57):2186-210.

35. Kynard B. Life history, latitudinal patterns, and status of the shortnose sturgeon, Acipenser brevirostrum. Environ Biol Fish. 1997;48:319-34.

36. Fernandes SJ, Zydlewski GB, Zydlewski JD, Wippelhauser GS, Kinnison MT. Seasonal distribution and movements of shortnose sturgeon and Atlantic sturgeon in the Penobscot river estuary, Maine. Trans Am Fish Soc. 2010;139:1436-49. doi:10.1577/T09-122.1.

37. Species at Risk Act, SC 2002, c 29.

38. COSEWIC. COSEWIC assessment and update status report on the shortnose sturgeon Acipenser brevirostrum in Canada. Ottawa: Committee on the Status of Endangered Wildlife in Canada; 2015.

39. Danylchuk SE, Danylchuk AJ, Cooke SJ, Goldberg TL, Koppelman J, Phillip DP. Effects of recreational angling on the post-release behavior and predation of bonefish (Albula vulpes): the role of equilibrium status at the time of release. J Exp Mar Biol Ecol. 2007:436:127-33.

40. Raby GD, Donaldson MR, Hinch SG, Patterson DA, Lotto AG, Robichaud D, English KK, Willmore WG, Farrell AP, Davis MW, Cooke SJ. Validation of reflex indicators for measuring vitality and predicting the delayed mortality of wild coho salmon bycatch released from fishing gears. J App Ecol. 2012:49:90-9. doi:10.1111/j.1365-2664.2011.02073.x. 
41. Cook KV, Lennox RJ, Hinch SG, Cooke SJ. Fish out of water: How much air is too much? Fisheries. 2015;40:452-61.

42. Trites RW. An oceanographical and biological reconnaissance of Kennebecasis Bay and the Saint John River Estuary. J Fish Res Board Can. 1960;17:377-408.

43. Hughes Clark JE, Parrott R. Integration of dense, time-varying water column information with high-resolution swath bathymetric data. US hydrographic conference, Norfolk VA, 1 May 2001.

44. Taylor $A D$, Litvak MK. Quantifying a manual triangulation technique for aquatic ultrasonic telemetry. N AM J Fish Manag. 2015;35:865-70. doi:10.1 080/02755947.2015.1059909.

45. Kedem B. Spectral analysis and discrimination by zero-crossings. Proc IEEE. 1986;74:1477-93. doi:10.1109/PROC.1986.13663.

46. Stein JY. Digital signal processing: a computer science perspective. New York: Wiley; 2000.

47. Long JH. Morphology, mechanics, and locomotion: the relation between the notochord and swimming motions in sturgeon. Environ Biol Fish. 1995:44:199-211.

48. Shepard ELC, Wilson RP, Halsey LG, Quintana F, Gómes Laich A, Gleiss AC, et al. Derivation of body motion via appropriate smoothing of acceleration data. Aquat Biol. 2008:4:235-41.

49. Nakamura I, Watanabe YY, Papastamatiou YP, Sato K, Meyer CG. Yo-yo vertical movements suggest a foraging strategy for tiger sharks Galeocerdo cuvier. Mar Ecol Prog Ser. 2011;424:237-46. doi:10.3354/meps08980.

50. Sakamoto KQ, Sato K, Ishizuka M, Watanuki Y, Takahashi A, Daunt F, Wanless S. Can ethograms be automatically generated using body acceleration data from free-ranging birds? PLoS One. 2009;4:e5379. doi:10.1371/ journal.pone.0005379.

51. Watanabe YY, Lydersen C, Fisk AT, Kovacs KM. The slowest fish: Swim speed and tail-beat frequency of Greenland sharks. J Exp Mar Biol Ecol. 2012;426:5-11. doi:10.1016/j.jembe.2012.04.021.

52. R Development Core Team. R: a language and environment for statistical computing. Vienna: R Foundation for Statistical Computing; 2013.

53. MATLAB R2012a Natick, Massachusetts: The MathWorks Inc WaveMetrics Inc., USA.

54. IgorPRO 6.3, WaveMetrics Inc., Ethographer Package, USA.

55. Petersen CGJ. The yearly immigration of young plaice into the Limfjord from the German Sea. Rep Dan Biol Stn Cph. 1896;6:5-30.

56. Deslauriers D, Kieffer JD. Swimming performance and behaviour of young-of-the-year shortnose sturgeon (Acipenser brevirostrum) under fixed and increased velocity tests. Can J Zool. 2012;90:345-51.

57. Geist DR, Brown RS, Cullinan V, Brink SR, Lepla K, Bates P, Chandler JA. Movement, Swimming speed, and oxygen consumption of juvenile white sturgeon in response to changing flow, water temperature, and light level in the Snake River, Idaho. Trans Am Fish Soc. 2005;134:803-16. doi:10.1577/T04-109.1.

58. Adams SR, Parsons GR, Hoover JJ, Kilgore KJ. Observations of swimming ability in shovelnose sturgeon (Scaphirhynchus platorynchus). J Freshw Ecol. 1997;12:631-3.

59. Kieffer JDK, Arsenault LMA, Litvak MKL. Behaviour and performance of juvenile shortnose Sturgeon Acipenser brevirostrum at different water velocities. J Fish Biol. 2009;74:674-82. doi:10.1111/j.1095-8649.2008.02139.x.

60. Broell F, Burnell C, Taggart CT. Measuring abnormal movements in freeswimming fish with accelerometers: implications for quantifying tag- and parasite-load. J Exp Biol. 2016;219:695-705. doi:10.1242/jeb.133033.

61. Collins MR, Cooke DW, Smith TIJ, Post WC, Russ DC, Walling DC. Evaluation of four methods of transmitter attachment on shortnose sturgeon, Acipenser brevirostrum. J Appl Icthyol. 2002;18:491-4.
62. Kieffer JD, Wakefiled AM, Litvak MK. Juvenile sturgeon exhibit reduced physiological responses to exercise. J Exp Biol. 2001;204:4281-9.

63. Baker DW, Wood AM, Litvak MK, Kieffer JD. Haematology of juvenile Acipenser oxyrinchus and Acipenser brevirostrum at rest and following forced activity. J Fish Biol. 2005;66:208-21. doi:1 0.1111/j.1095-8649.2004.00595.

64. Cooke SJ, Donaldson MR, O'Connor CM, Raby GD, Arlinghaus R, Danylchuk AJ, Hanson KC, Hinch SG, Clark TD, Patterson DA, Suski CD. The physiological consequences of catch-and-release angling: perspectives on experimental design, interpretation, extrapolation, and relevance to stakeholders. Fish Manag Ecol. 2013;20:268-87.

65. Robinson KA, Hinch SG, Raby GD, Donaldson MR, Robichaud D, Patterson DA, Cooke SJ. Influence of postcapture ventilation assistance on migration success of adult Sockeye Salmon following capture and release. Trans Am Fish Soc. 2015;144(4):693-704. doi:10.1080/00028487.2015.103 1282.

66. Jepsen N, Thorstad EB, Havn T, Lucas MC. The use of external electronic tags on fish: an evaluation of tag retention and tagging effects. Anim Biotel. 2015;3:49. doi:10.1186/s40317-015-0086-z

67. Webb PW. Kinematics of lake sturgeon, Acipenser fulvescens, at cruising speeds. Can J Zool. 1986;64:2137-41.

68. Peake S, Beamish FWH, McKinley RS, Scruton DA, Katopodis C. Relating swimming performance of lake sturgeon, Acipenser fulvescens, to fishway design. Can J Fish Aquat Sci. 1997;54:1361-6.

69. Wilga CD, Lauder GV. Locomotion in sturgeon: function of the pectoral fin. J Exp Biol. 1999;202:2413-32

70. Cheong TS, Kavvas EML, Andreson EEK. Evaluation of adult white sturgeon swimming capabilities and applications to fishway design. Environ Biol Fish. 2006;77:197-208. doi:10.1007/s10641-006-9071-y.

71. Watanabe YY, Wei Q, Yang D, Chen X, Du H, Yang J, Sato K, Naito Y, Miyazaki N. Swimming behaviour in relation to buoyancy in an open swimbladder fish, the Chinese sturgeon. J Zool. 2008;275:381-90. doi:10.1111/j.1469-7998.2008.00451.x.

72. Marras S, Noda T, Steffensen JF, Svendsen MBS, Krause J, Wilson ADM, Kurvers RHJM, Herbert-Read J, Boswell KM, Domenici P. Not So Fast: Swimming behavior of sailfish during predator-prey interactions using high-speed video and accelerometry. Integr Comp Biol. 2015;55:719-27. doi:10.1093/icb/icv017.

73. Hunter E, Metcalfe JD, Holford BH, Arnold GP. Geolocation of free-ranging fish on the European continental shelf as determined from environmental variables II. Reconstruction of plaice ground-tracks. Mar Biol. 2004;144:787-98. doi:10.1007/s00227-003-1242-1.

74. Gröger JP, Rountree RA, Thygesen UH, Jones D, Martins D, Xu Q, Rothschild BJ. Geolocation of Atlantic cod (Gadus morhua) movements in the Gulf of Maine using tidal information. Fish Oceanogr. 2007;16:317-35. doi:10.1111/j.1365-2419.2007.00433.x.

75. Ropert-Coudert R, Wilson RP. Subjectivity in bio-logging science: do logged data mislead? Mem Natl Inst Polar Res Spec Issue. 2004;58:23-33.

76. Metcalfe CD, Dadswell MJ, Gillis GF, Thomas MLH. Physical, chemical, and biological parameters of the Saint John River Estuary, New Brunswick, Canada. Fisheries and Marine Service Canada technical report 1976;686.

\section{Submit your next manuscript to BioMed Central and we will help you at every step:}

- We accept pre-submission inquiries

- Our selector tool helps you to find the most relevant journal

- We provide round the clock customer support

- Convenient online submission

- Thorough peer review

- Inclusion in PubMed and all major indexing services

- Maximum visibility for your research

Submit your manuscript at www.biomedcentral.com/submit
BioMed Central 